\title{
Remittances, Remittance Concentration, and Volatility: Is Africa Different from the Middle East?
}

\author{
Amr Hosny \\ International Monetary Fund, 700 19th Street, N.W., Washington, D.C. 20431, USA
}

Tel: 202-623-4472Ｅ-mail: ahosny@imf.org

Received: June 29, 2019 Accepted: July 16, 2019 Published: July 27, 2019

doi:10.5296/ber.v9i3.14994 URL: https://doi.org/10.5296/ber.v9i3.14994

\begin{abstract}
This paper makes a new contribution to the empirical literature on the macroeconomic consequences of remittances using data over 1970-2015 period for 56 African and Middle Eastern countries to study the impact of (i) large remittance inflows and (ii) high concentration of origin of remittance on the volatilities of real GDP growth, exports-to-GDP ratio, nominal exports growth and nominal exchange rate depreciation. We find that (i) large remittances can reduce all types of volatility, especially in African countries, and (ii) high remittance concentration, by itself, has been associated with higher volatilities in African but not Middle Eastern countries, and that having both high remittances, but also high concentration aggravates all types of volatility in both regions, although results for the Middle East are not always conclusive.
\end{abstract}

Keywords: Remittances, Volatility, Remittance concentration, Africa, Middle East

JEL Classification Codes: E32, F24, O19

\section{Introduction and Contribution to the Literature}

Remittance flows have grown rapidly over the past decades. Worldwide remittances in 2011 surpassed $\$ 500$ billion a year according to World Bank data. As of end 2015, remittances reached around $\$ 581$ billion. This rising trend is expected to continue as migration from developing to more developed countries persists.

In the Middle East and North Africa (MENA) and Sub-Saharan Africa (AFR) regions, remittances are considered an important source of foreign exchange, in some countries even exceeding export revenues. In 2015, remittance flows to MENA countries surpassed $\$ 50$ billion. In AFR countries, remittances reached $\$ 37$ billion in $2015 .^{1}$ These are substantial

\footnotetext{
${ }^{1}$ Data comes from the World Bank World Development Indicators (WB-IDS) database available here: http://data.worldbank.org/data-catalog/world-development-indicators
} 
amounts of foreign exchange, that in some cases can even surpass the export proceeds of a country. These flows are becoming increasingly important as they can help countries withstand economic shocks and foster development projects, as well as their consumption smoothing impact at the household level.

A large strand of the literature examines the determinants of remittance inflows. Remittances are generally linked to migration patterns, economic activity in host country, economic activity in home country, institutions in home country, economic policies in home country, risks in home country, and/or investment opportunities in host versus home country. For a thorough discussion, see IMF (2005), World Bank (2006a), World Bank (2006b), Chami et al (2008), Ebeke (2011), Ncube and Brixiova (2013), and World Bank (2015), among others.

Several studies examined the potential positive development impact of remittances. At the household level, remittances can be associated with increased consumption, reductions in poverty, and possibly even reductions in inequality (IMF 2005). Tansel, and Yaşar (2010) find that emittances can increase consumption and investments in Turkey using data over 1964-2003. IMF (2005) argues that remittances can even reduce the probability of financial crisis in some extreme cases. Hassan and Shakur (2017) find evidence of a non-linear relationship between remittances and per capita GDP growth in Bangladesh, where better social and economic incentives led to more productive use of remittances in later stages. Bang et al (2016) test the impact of remittances on household expenditures using data from the Kenyan Migration Household Survey, and by employing an instrumental variable quantile regression model, they find that while remittances increase household expenditure at all levels of the expenditure distribution, the impact is unambiguously greatest for poorer households. Hence, they conclude that remittances, in and of themselves, improve both poverty and the distribution of income. Using data from the Nepal Living Standards Survey, Thapa and Acharya (2017) find that remittance recipient households in Nepal tend to spend more on consumption, health and education as compared to remittance non-receiving households.

Recent studies examine the specific impact of remittances on reducing volatility of different economic variables. For example, IMF (2005) estimates that worker's remittances in remittance-dependent countries, defined as those where remittance-to-GDP ratio exceeds 1 percent of GDP in a board sample of more than 100 countries over the 1970-2003 period, can lower output and consumption volatility, thus helping to stabilize economic activity ion recipient countries. Ahmed, and Martínez-Zarzoso (2013) find that remittances have a counter-cyclical mechanism with output in Pakistan. Chami, Hakura, and Montiel (2012) use panel and GMM methods to provide evidence that remittances can reduce the volatility of GDP growth in a sample of 16 advanced and 54 developing remittance-receiving countries over 1970-2004, after controlling for other factors that may influence growth volatility such as macro environment and institutions. World Bank (2006b) finds that remittances can reduce GDP volatility, while World Bank (2015) finds that remittances can help improve consumption stability. Chami et al (2008) find that an increase in worker's remittances-to-GDP ratio of one percentage point leads to a reduction of 0.164 percent in the GDP growth volatility, measured as the standard deviation of GDP growth. 
There is also documentation in the literature about the potential negative development impact of remittances. Chami, Fullenkamp, and Jahjah (2003), using panel methods on a large sample of 83 countries over the 1970-1998 period, estimate that remittances can have a negative impact on growth through lowering incentives to work, due to a moral hazard problem as remittances can take place under asymmetric information and economic uncertainty. IMF (2005) and World Bank (2006a) argue that large remittances can lead to real exchange rate appreciation, lower export competitiveness, and a contraction of tradable sectors (the Dutch disease), and they find no statistically significant direct link between remittances and per capita output growth, education or investment. Jansen, Vacaflores, and Naufal (2012) find that a remittances shock can produce a decline in GDP, that can only be diminished when remittances are a larger percentage of GDP.

Studies specific to the AFR region are limited, but find that remittances can reduce output volatility. For example, Ncube and Brixiova (2013) find that remittances are positively impacted by higher income, but harmed by unstable macroeconomic environments. Jidoud (2015) uses a DSGE model to find that remittances as a share of GDP can have a significant smoothing effect on output volatility, but a smaller impact on consumption volatility.

Studies specific to the MENA region are limited, but find that remittances can smooth growth volatility in some cases. For Egypt, Ncube and Brixiova (2013) find that rising remittances can have a positive impact on public debt sustainability. For Morocco, Bouoiyour, Selmi, and Miftah (2016) find that remittances can smooth volatility of growth, while FDI flows can aggravate it.

In this paper, we aim to contribute to the existing literature in two ways. First, we study the potential positive impact of large remittance inflows on smoothing volatility of a wide range of economic variables, filling an important gap in the literature which often focuses on growth or exports volatility only. Second, we study the neglected potential negative impact of high geographic concentration of origin of remittances on these same volatilities. The motivation here is to quantitatively examine the potential negative impact of high geographic concentration of remittances, notwithstanding the potential positive impact of high remittances themselves.

Specifically, first we study the impact of large remittances inflows on the volatility of a wide range of economic variables. We namely consider the effect of remittances on the volatility of real GDP growth, volatility of exports-to-GDP ratios, volatility of nominal exports growth, and volatility of exchange rate depreciations. This is a contribution to the literature in the sense of studying all such volatilities together, whereas existing studies tend to focus more on GDP growth volatility, and limited or no studies to the best of our knowledge that examine the impact of remittances on volatility of exchange rate depreciation for example.

Second, we study the potentially negative role that the geographic concentration for the sources of remittances can have on volatilities, notwithstanding the positive impact of large remittances themselves. Theoretically, if a remittance receiving country largely depends on a single source/country for its remittances, then negative shocks or developments in the remittance sending country would potentially have a negative impact on reducing the 


\section{Macrothink Institute ${ }^{\mathrm{TM}}$}

recipient country's volatilities. We could not find studies in the literature examining the role of geographic concentration of the origin of remittances on smoothing economic volatilities a country can face. In this regard, our study is a clear contribution to the literature.

To the best of our knowledge, this is the first study in the literature to examine such a wide range of volatilities, plus explicitly introducing the role of high remittance concentration. Combining both objectives of this study, namely examining the positive role of remittances as well as the negative role of high remittance concentration on economic volatilities, we aim to shed light on a new direction in the literature. We focus on the MENA and AFR regions, two regions which receive and depend on high remittance inflows.

This paper is structured as follows. After the motivation and literature review in this first section, Section II will take a closer look at the remittance and remittance concentration data in MENA and AFR countries. Section III will explain the empirical methodology and present the results of the regressions of the impact of large remittances as well as high remittance concentration on volatilities of different economic variables. Finally, Section IV will summarize and conclude.

\section{An Initial Look at the Data}

Remittances are an important source of foreign currency to several MENA countries. This is especially the case for Lebanon and Jordan (above 15 percent of GDP on average over 1970-2015), followed by Yemen, Morocco, and Egypt (above 5 percent of GDP over the same period). These countries remittances-to-GDP ratio exceed the average ratio for MENA countries at around 5 percent of GDP (vertical line in Figure 1, panel A). In terms of absolute values on average over the 2000-2015 period (see Figure 1, panel B), Egypt received the most remittances (above $\$ 8$ billion), followed by Lebanon and Morocco (above $\$ 5$ billion each). These countries largely depend on remittances as a stable source of foreign currency income.
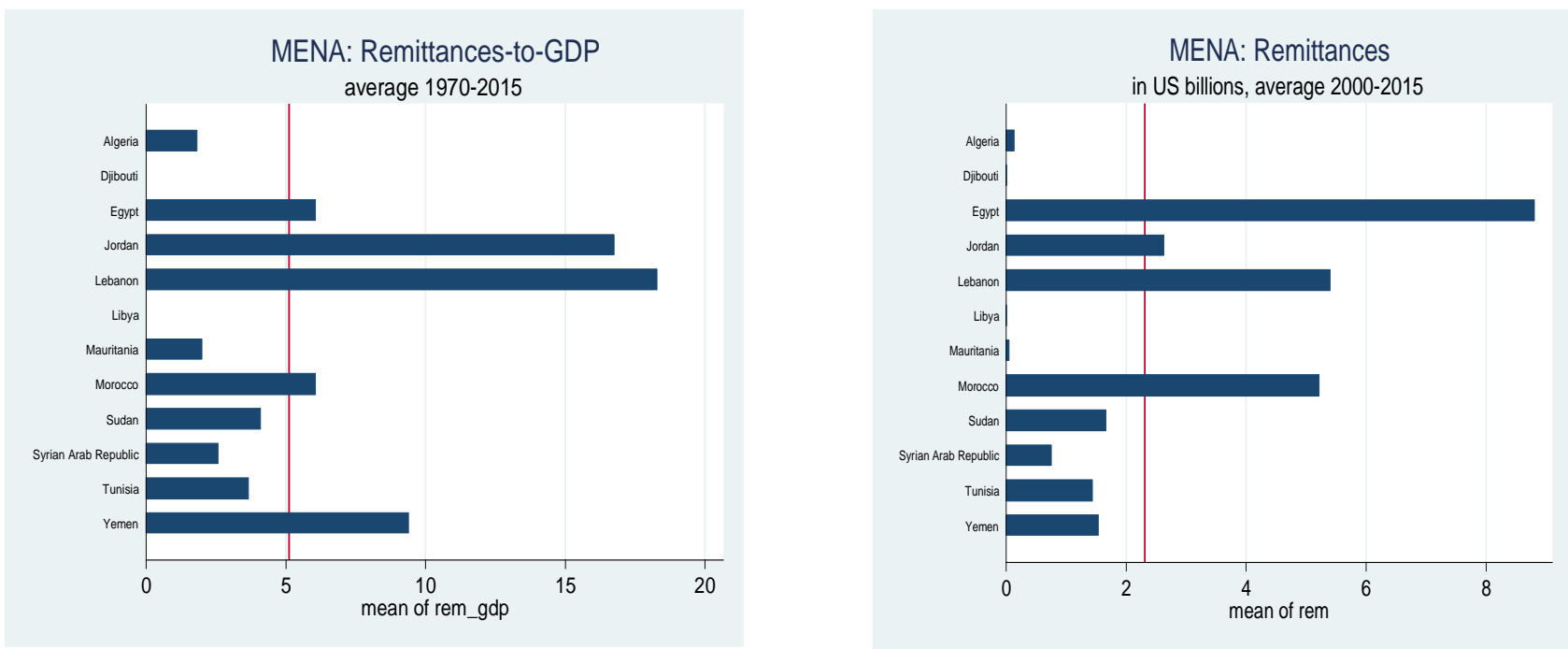

Figure 1. MENA Remittances (ratio to GDP and in US\$ bn) 


\section{Macrothink}

Business and Economic Research

ISSN 2162-4860

2019, Vol. 9, No. 3

Remittances are even a relatively more important source of foreign currency in many AFR countries. Several AFR countries have remittance-to-GDP ratios above 5 percent, the average ratio for the AFR group as a whole (Figure 2, panel A). One can see that countries like Eritrea (close to 40 percent) and Lesotho (close to 30 percent) have remittance-to-GDP ratios above 20 percent, while Liberia and Cabo Verde have ratios exceeding 10 percent. In absolute values over the period 2000-2015, Nigeria received the highest remittances by far, reaching around $\$ 13$ billion on average over the period. Then comes Ghana, Senegal, and Ethiopia with amounts around $\$ 1.5$ billion a year on average over the same period (Figure 2, panel B).

The geographic concentration of remittances is an important angle, often missed in the empirical literature. Although many empirical studies in the literature studied remittances and their effect on a country's health, very few have looked into the effects of the concentration of remittances.

We use the Herfindahl-Hirschman Index (HHI) to measure remittances concentration. The $\mathrm{HHI}$ is a widely-used measure of concentration. In our context, this would entail measuring the size of remittances received from each country in relation to overall remittances. It is defined as the sum of the squares of the shares of remittance sending countries to all countries, where shares are expressed as fractions, producing a range between 0 and 10,000 points, which we then normalize to be become an index between 0 and 1. A higher HHI indicates higher concentration. In what follows, we use annual remittance data, by country, from the WB over the period 2010-2015. ${ }^{2}$
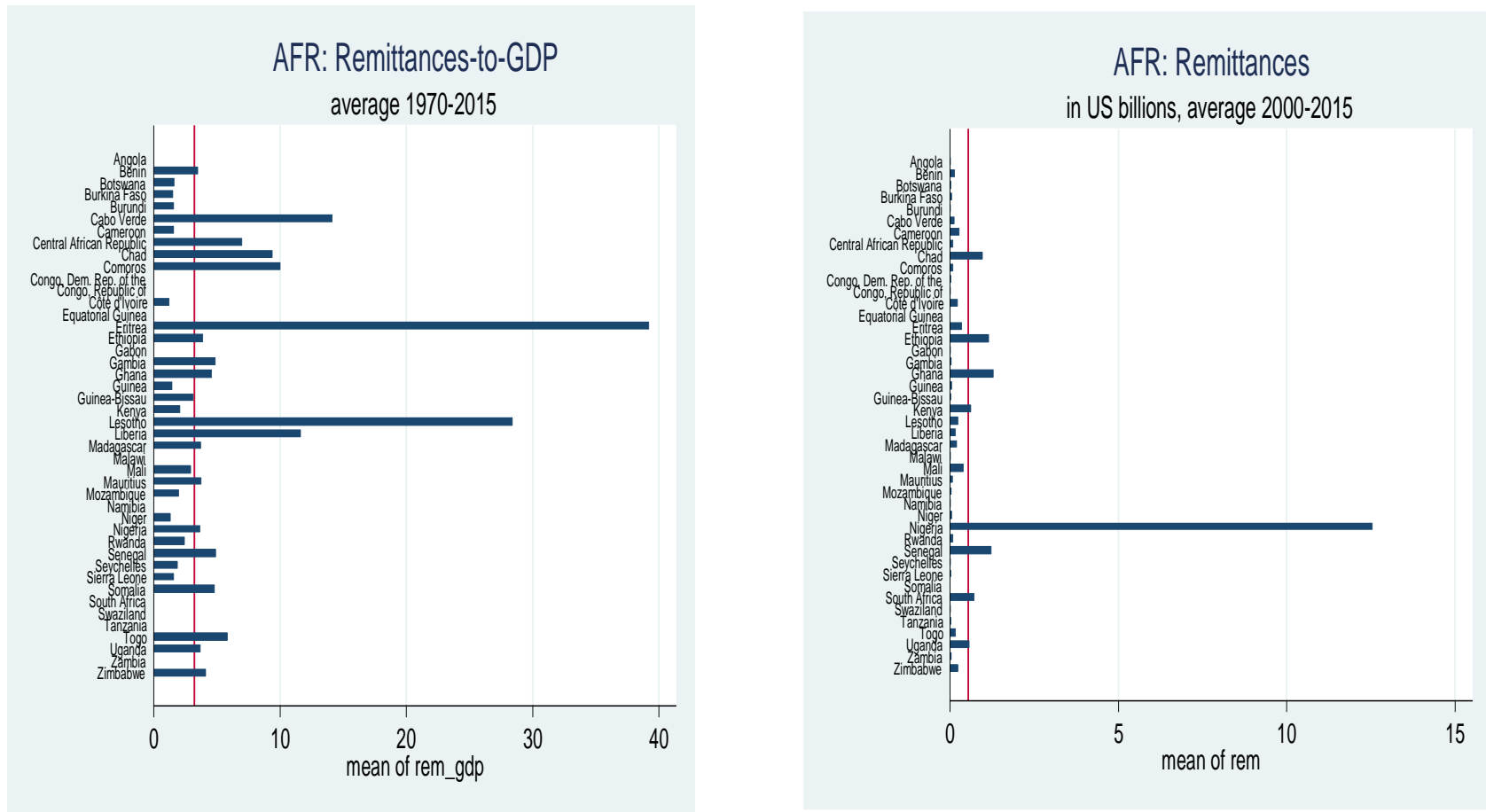

${ }^{2}$ Data is available online on the World Bank website:

https://www.worldbank.org/en/topic/migrationremittancesdiasporaissues/brief/migration-remittances-data 
Figure 2. AFR Remittances (ratio to GDP and in US\$ bn)

In the MENA region, 4 countries have high geographic remittance concentrations, mostly originating from European or Gulf countries. Using the average of the HHI index over 2010-2015 for our group of MENA countries, we find that concentration in Algeria, Djibouti, Tunisia and Yemen is above the MENA average concentration (Figure 3). France is the main source of remittances for Algeria, Djibouti and Tunisia, while Saudi Arabia is the main source of remittances for Yemen. Countries like Egypt and Jordan have less concentrated sources, mostly from several Gulf countries (Saudi Arabia, UAE and Kuwait), while Lebanon is the most diversified, with its remittances coming mostly from Saudi Arabia, United States, Germany and Canada.

In the AFR region, 9 countries have geographic concentrations above the regional average, mostly origination from South Africa and to a lesser extent from France. Specifically, Lesotho and Swaziland recorded the highest geographic remittance concentration over 2010-2015, with an average HHI over 0.8 and remittances almost entirely origination from South Africa. Namibia, Mozambique and Botswana's remittances are also mostly from South Africa, while Madagascar and Comoros's remittances mostly originate from France. Burkina Faso's remittances originate mostly from Cote d'Ivoire, while most of Cote d'Ivoire's remittances originate from Burkina Faso. Figure 4 provides the details for all AFR countries.

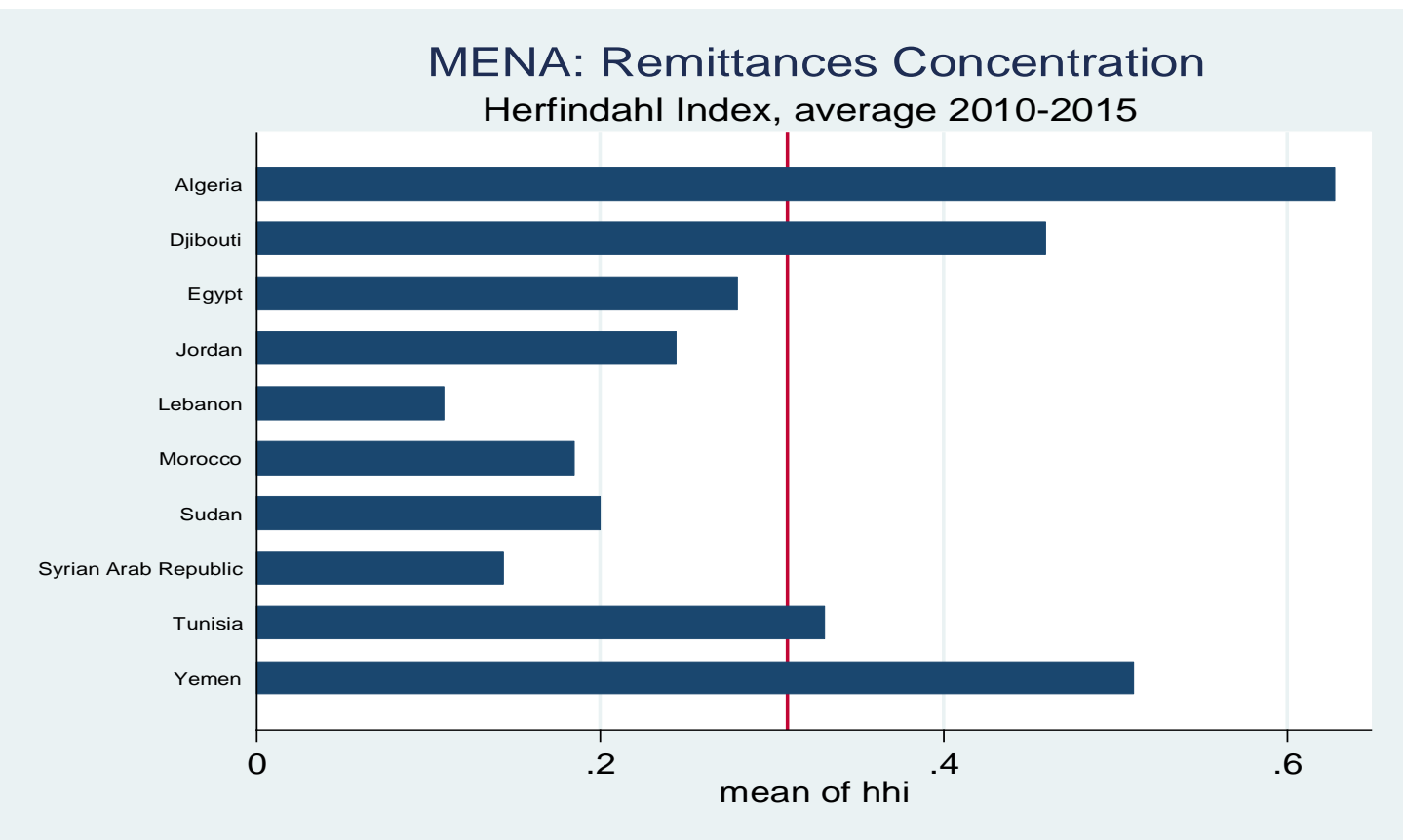

Figure 3. MENA Remittances Concentration 


\section{I Macrothink}

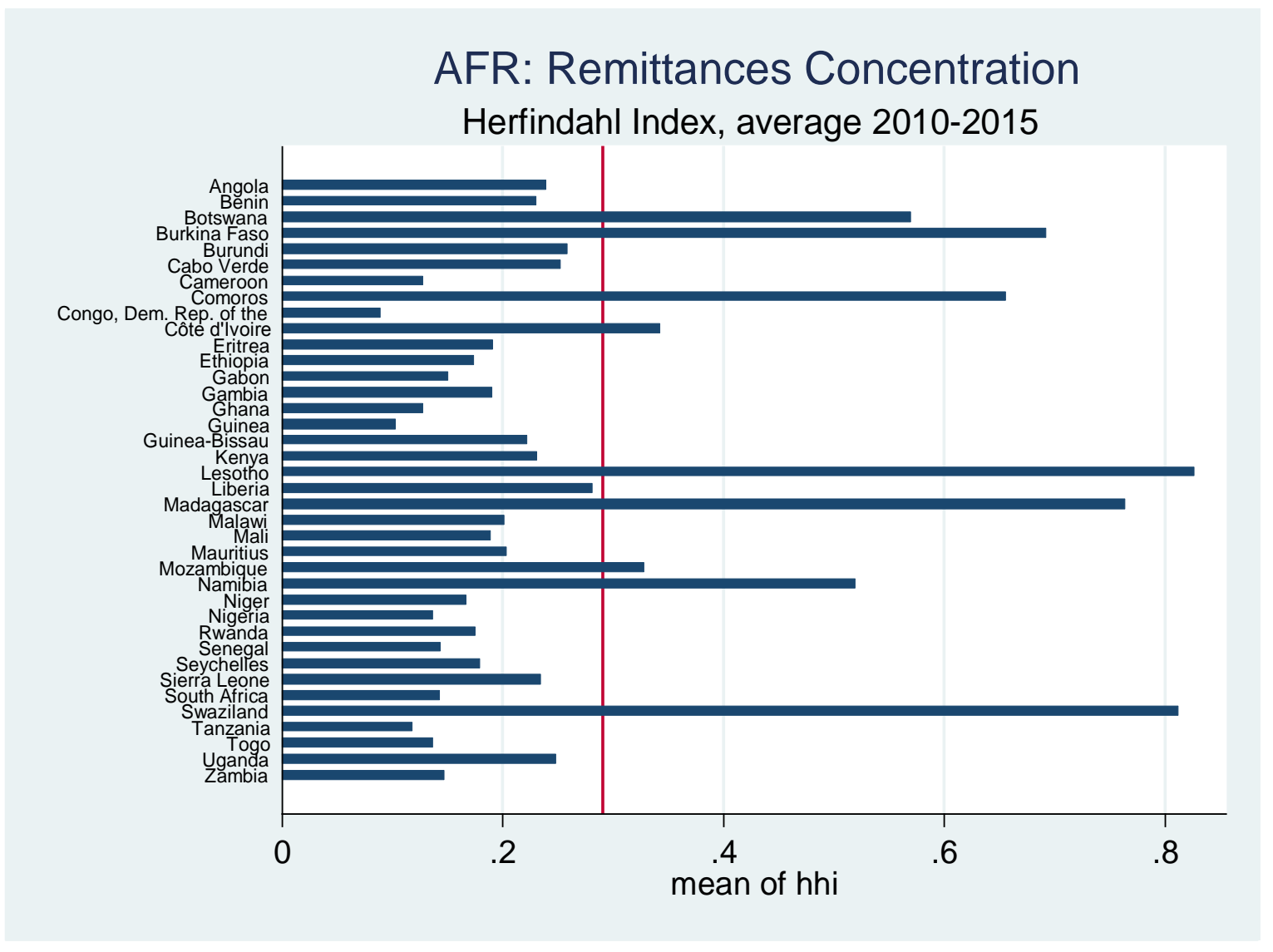

Figure 4. AFR Remittances Concentration

We are interested in measuring the effect of remittances and their geographic concentration on volatility of growth, exports and exchange rates of MENA and AFR countries. To do that, we create volatility measures of real GDP growth, exports growth, exports-to-GDP ratio, and exchange rate depreciation. To create the measure of volatility, we use a rolling 10-year window of standard deviation of these variables. An illustration is provided below.

Among MENA countries, growth volatility is the highest in Lebanon. Figure 5 provides an estimation of real GDP growth volatility for our MENA sample over the 1970-2015 period using data from IMF WEO. Lebanon has the highest volatility compared to other countries in the same region, followed by Libya, Sudan and Syria. In this region, Egypt has had the lowest growth volatility over our sample period. Lebanon's case is interesting as it reported the highest average remittances-to-GDP ratio in the region (see Figure 1), but has the lowest remittance concentration (see Figure 3), while at the same time having the highest growth volatility (Figure 5).

Among AFR countries, growth volatility was highest in Liberia and Equatorial Guinea. Figure 6 shows that by far Liberia and Equatorial Guinea had had the highest volatility of real GDP growth over the 1970-2015 period in the AFR region. These are followed by Zimbabwe, Sierra Leone, Zambia, and Rwanda. 


\section{Macrothink}

Business and Economic Research

ISSN 2162-4860 2019, Vol. 9, No. 3

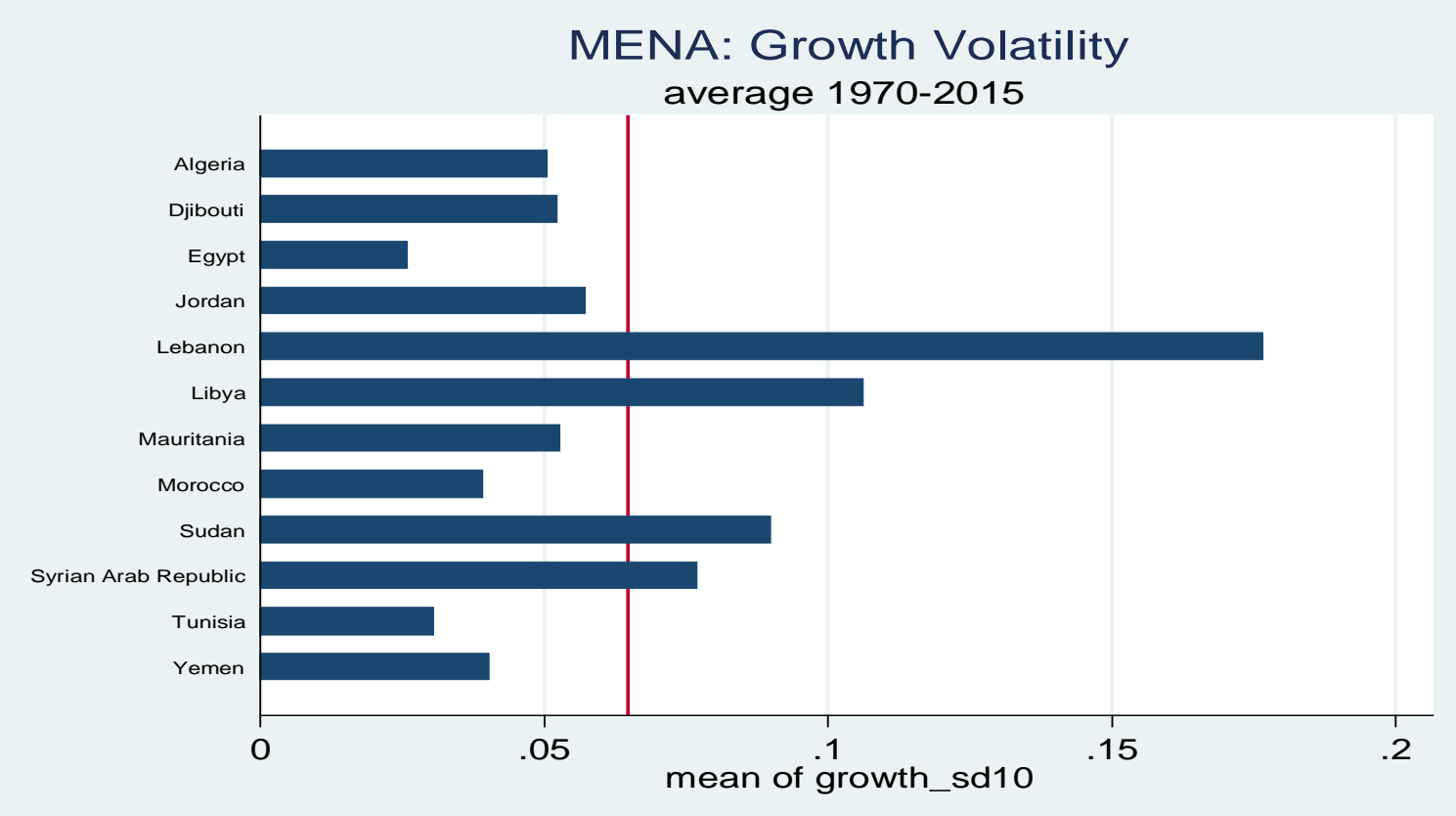

Figure 5. MENA Growth Volatility

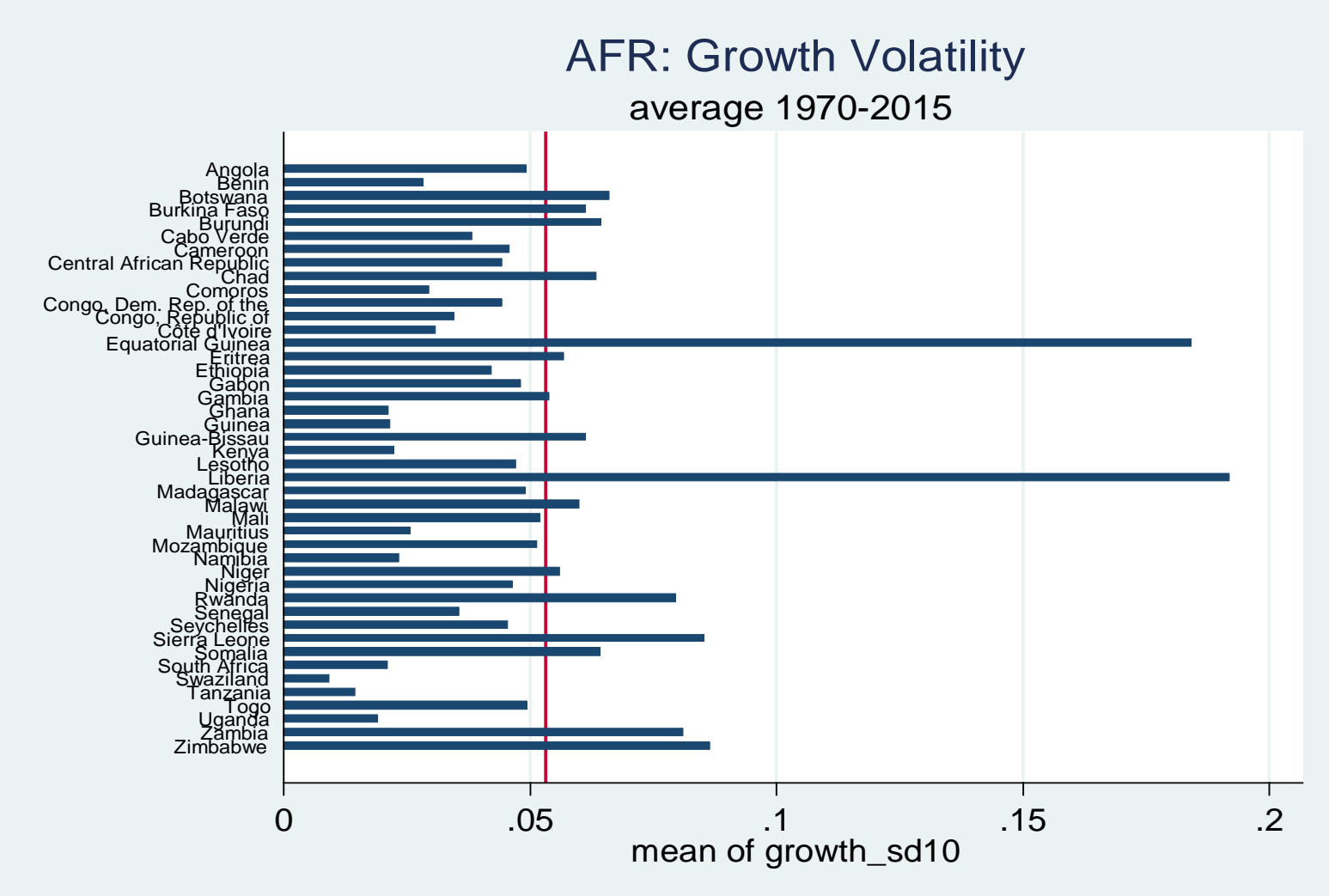

Figure 6. AFR Growth Volatility 


\section{Empirical Methodology and Results}

We use pooled OLS to study the association between economic volatilities (LHS explained variable) and large remittances and high remittance concentration among other factors (RHS explanatory variables). We use data over the period 1970-2015, where available, building on different sources but mostly from the IMF WEO and the WB WDI databases. Our focus is on AFR and MENA countries as these are two regions that receive and depend on remittances the most.

Concerning the first explanatory variable of interest, we create a dummy variable to capture large remittance countries. Specifically, we create a dummy variable that takes the value of one if, for a given county, for a given year, remittances to GDP were equal to or higher than 10 percent of GDP (rem_dummy10). This follows the definition of large remittance countries used by IMF (2013). The dummy would take the value of zero otherwise. Similarly, we create another indicator variable that take the value of one if remittances are equal to or higher than 1 percent of GDP, and zero otherwise (rem_dummy1). This latter measure follows the definition laid out in IMF (2005) and World Bank (2015). The idea is to see whether countries with large remittance can weather volatilities of growth, exports and the exchange rate better than countries with low remittances.

Regarding the second explanatory variable of interest, we use the Herfindahl-Hirschman Index (HHI) to measure geographic remittances concentration. As mentioned in the previous section, the HHI measures the size of remittances received from each country in relation to overall remittances. A higher HHI indicates higher concentration. We use annual remittance data, by country, from the World Bank over the period 2010-2015. In the regressions, we calculate the average of the HHI index over the 2010-2015 period where data is available (hhi_mean1015), and we assume this value is the same over the 1970-2015 period, to not lose a big portion of the observations in the regressions. As a robustness check, we experiment with using the 2013-2015 average instead, and we also use the individual HHI annual values for the 2010-2015 period.

The Country Policy and Institutional Assessment (CPIA) variable is our measure of quality of institutions as an additional explanatory variable. ${ }^{3}$ The CPIA is an annual index, published by the World Bank, providing a rating of countries over a set of 16 different criteria grouped into four broad clusters: namely economic management, structural policies, policies for social inclusion and equity, and public sector management and institutions. The CPIA goes from 1 (low/weak institutions) to 6 (high/better institutions). Other explanatory variables include initial GDP level, trade openness, real effective exchange rate, and the change in oil prices.

\subsection{GDP Growth Volatility}

Starting with GDP volatility, large remittances seem to be associated with lower volatility in AFR but not in MENA. This is evident from the negative and statistically significant coefficient attached to the large remittances dummy, when large remittances are defined as those with remittances of 1 percent of GDP or larger (Table 1). This is not the case for MENA

\footnotetext{
${ }^{3}$ The CPIA data is available here: http://data.worldbank.org/data-catalog/CPIA
} 
countries, where the coefficient is not statistically significant, and is even showing a positive sign. The coefficient is not significant for both AFR and MENA when large remittances are defined as those with 10 percent of GDP or more.

Remittance concentration seems to be correlated with an increase in volatility in large remittance countries in both AFR and MENA countries. Focusing on the impact of remittances concentration, we find that the interaction dummy between high remittances and the HHI index of concentration is positive and statistically significant in both the cases of AFR and MENA (see equations 3 and 4 in Table 1). This suggests that high geographic concentration of the origin of remittances in these two regions, on average, is associated with higher growth volatility in countries with large remittances-to-GDP ratios. This implies that although high remittances by themselves can lower volatility, high concentration of remittances may in fact increase GDP growth volatility.

Better institutions in both AFR and MENA are associated with lower GDP growth volatility as expected. The coefficient attached to the institutions variable is shown to be negative and highly statistically significant (see Table 1), implying that countries with better institutions are better equipped to lower their volatilities of GDP growth. Policymakers in both these regions can, therefore, know that improving institutions would not all entail the usual benefits of doing so, but would also help lower volatility of growth, all else held constant.

Table 1. Volatility of GDP Growth

\begin{tabular}{|l|l|l|l|l|}
\hline & MENA & AFR & MENA & AFR \\
\hline & $(1)$ & $(2)$ & $(3)$ & $(4)$ \\
\hline VARIABLES & growth vol & growth vol & growth vol & growth vol \\
\hline & & & & \\
\hline rem_dummy10 & 0.034 & 0.004 & & \\
\hline & $(0.026)$ & $(0.004)$ & & \\
\hline rem_dummy1 & & & 0.004 & $-0.011^{* * *}$ \\
\hline & & & $(0.008)$ & $(0.003)$ \\
\hline hhi_mean1015 & -0.080 & 0.001 & -0.609 & -0.006 \\
\hline & $(0.352)$ & $(0.014)$ & $(0.446)$ & $(0.013)$ \\
\hline rem_dummy10hhi1015 & -0.071 & -0.009 & & \\
\hline & $(0.085)$ & $(0.012)$ & & \\
\hline rem_dummy1hhi1015 & & & $0.040^{* *}$ & $0.032^{* * *}$ \\
\hline & & & $(0.020)$ & $(0.011)$ \\
\hline Initialgdp & -0.012 & $-0.008^{* * *}$ & 0.018 & $-0.009 * * *$ \\
\hline & $(0.026)$ & $(0.002)$ & $(0.026)$ & $(0.002)$ \\
\hline L.openness & $-0.028 * * *$ & $-0.010^{* *}$ & $-0.024 * *$ & -0.010 \\
\hline & $(0.011)$ & $(0.004)$ & $(0.010)$ & $(0.007)$ \\
\hline L.cpia & $-0.011 * *$ & $-0.012^{* * *}$ & $-0.010^{* *}$ & $-0.012 * * *$ \\
\hline & $(0.005)$ & $(0.001)$ & $(0.005)$ & $(0.002)$ \\
\hline L.reer & -0.000 & $-0.000^{* * *}$ & -0.000 & $-0.000^{* * *}$ \\
\hline & $(0.000)$ & $(0.000)$ & $(0.000)$ & $(0.000)$ \\
\hline & & & &
\end{tabular}




\begin{tabular}{|l|l|l|l|l|}
\hline & MENA & AFR & MENA & AFR \\
\hline & $(1)$ & $(2)$ & $(3)$ & $(4)$ \\
\hline VARIABLES & growth vol & growth vol & growth vol & growth vol \\
\hline L.doil_price & -0.008 & 0.001 & -0.007 & 0.002 \\
\hline & $(0.007)$ & $(0.002)$ & $(0.007)$ & $(0.002)$ \\
\hline Constant & 0.135 & $0.096^{* * *}$ & $0.273^{* *}$ & $0.099 * * *$ \\
\hline & $(0.108)$ & $(0.009)$ & $(0.111)$ & $(0.009)$ \\
\hline & & & & \\
\hline Observations & 359 & 1,610 & 359 & 1,610 \\
\hline R-squared & 0.506 & 0.492 & 0.506 & 0.494 \\
\hline dummy & rem>10 & rem>10 & rem>1 & rem>1 \\
\hline method & OLS & OLS & OLS & OLS \\
\hline
\end{tabular}

Standard errors in parentheses; $* * * \mathrm{p}<0.01, * * \mathrm{p}<0.05, * \mathrm{p}<0.1$. Country dummies included but not shown in OLS regressions. "rem_dummy10" is the large remittance dummy variable using the 10 percent of GDP definition; "rem_dummyl" is the large remittance dummy variable using the 1 percent of GDP definition; "hhi_mean1015" is the HHI index based on the 2010-2015 average; "rem_dummy10hhi1015" is the interaction dummy between the large remittance dummy based on the 10 percent definition and the HHI index; "rem_dummy1hhi1015" is the interaction dummy between the large remittance dummy based on the 1 percent definition and the HHI index; "Initialgdp" is GDP level in first sample year; "L.openness" is lagged trade openness; "L.cpia" is lagged CPIA used as a proxy for quality of institutions; "L.reer" is lagged real effective exchange rate from the IMF World Economic Outlook database; and "L.doil_price" is the lagged change in oil price coming from IMF World Economic Outlook database.

There is also evidence that increased openness is associated with lower GDP growth volatility. Results suggest that countries with higher openness, measured as the share of exports plus imports to GDP, are associated with lower volatilities of growth, holding all else equal. This is an encouraging sign to policymakers, as increased openness would not only make the economy more competitive but would also help lessen volatilities. In this context, Mitra et al (2016) reports evidence that increased trade openness in MENA countries, especially with fast-growing economies with integrated manufacturing chains, can help bolster productivity.

Other results suggest that a higher initial GDP level is associated with lower GDO growth volatility in AFR countries (equations 2 and 4 in Table 1), while REER and oil price changes do not seem to impact growth volatility in either region.

\subsection{Exports-to-GDP volatility}

Turning to the volatility of exports-to-GDP, results suggest large remittances are associated with lower volatility. This is the case for AFR, as evidenced by equations 6 and 8 representing remittances equal to or above 10 and 1 percent of GDP, respectively, in Table 2. In MENA, the coefficient is also negative and statistically significant in equation 5 with large remittances defined as those equal to or above 10 percent, but not in equation 7 with large 
remittances defined as equal to or above 1 percent of GDP (although the sign is still negative, as one would expect).

High remittance concentration is detrimental to the volatility of exports-to-GDP ratio in AFR, but not in MENA, all else equal. The coefficient attached to the HHI index is positive and statistically significant only in the case of AFR countries (see equations 6 and 8 in Table 2). This implies that, all else equal, high concentration of remittances is correlated with increases in volatility of exports-to-GDP ratio in this region. In the case of MENA countries, the same coefficient is in fact negative, showing the unexpected sign, when large remittances are defined as those equal to or above 1 percent of GDP (see equation 7 of Table 2). The coefficient is also negative but bit statistically significant in equation 5 where large remittances are those equal to or above 10 percent of GDP.

When combined with high remittance concentration, large remittances are associated with increases in volatility in both AFR and MENA countries (see equations 5, 6 and 8 in Table 2). Looking at the dummy of interest, one can conclude that high remittances when coupled with high geographic concentration of the country of origin of remittances, are correlated with a worsening of volatility (the coefficient is positive and statistically significant).

Better institutions are associated with lower volatility in both AFR and MENA. Empirical results suggest that higher CPIA values are associated with lower export-to-GDP volatility, as one would expect. This is the case in all cases, except for equation 7 for MENA countries when large remittances are defined as those equal or above 1 percent of GDP, where the coefficient is in fact positive and significant, giving the counterintuitive impression that better institutions are associated with even higher volatility.

Higher levels of lagged real effective exchange rates are associated with lower volatility in AFR and MENA. ${ }^{4}$ This is true for MENA and AFR when using the 10 percent definition of large remittances, also for AFR when using the 1 percent definition, but not for MENA when using the 1 percent definition.

Changes in oil prices, which act as a proxy for dependence on natural resources and/or global shocks potentially affecting both the source and recipient countries, do not seem to be correlated with volatility of exports-to-GDP in both regions. Empirical results in all equations are not statistically significant.

Table 2. Volatility of Exports-to-GDP

\begin{tabular}{|l|l|l|l|l|}
\hline & MENA & AFR & MENA & AFR \\
\hline & $(5)$ & $(6)$ & $(7)$ & $(8)$ \\
\hline VARIABLES & ex_gdp vol & ex_gdp vol & ex_gdp vol & ex_gdp vol \\
\hline & & & & \\
\hline rem_dummy10 & $-3.253^{* *}$ & $-1.757^{* * *}$ & & \\
\hline & $(1.404)$ & $(0.363)$ & & \\
\hline rem_dummy1 & & & -16.887 & $-1.436^{* * *}$ \\
\hline
\end{tabular}

\footnotetext{
${ }^{4}$ The real effective exchange rate is defined such that lower values over time indicate a depreciation.
} 


\begin{tabular}{|c|c|c|c|c|}
\hline & MENA & AFR & MENA & AFR \\
\hline & (5) & (6) & (7) & (8) \\
\hline \multirow[t]{2}{*}{ VARIABLES } & ex_gdp vol & ex_gdp vol & ex_gdp vol & ex_gdp vol \\
\hline & & & (13.528) & $(0.325)$ \\
\hline \multirow[t]{2}{*}{ hhi_mean1015 } & -11.803 & $1,184.989 * * *$ & $-74.120 * * *$ & $930.175^{* * *}$ \\
\hline & $(8.193)$ & (241.076) & $(25.441)$ & (190.293) \\
\hline \multirow[t]{2}{*}{ rem_dummy10hhi1015 } & $14.913 * * *$ & $1.703 * *$ & & \\
\hline & $(4.945)$ & $(0.776)$ & & \\
\hline \multirow[t]{2}{*}{ rem_dummy1hhi1015 } & & & 26.706 & $3.061 * * *$ \\
\hline & & & $(22.359)$ & $(0.962)$ \\
\hline \multirow[t]{2}{*}{ L.cpia } & $-1.040^{*}$ & $-0.247 * *$ & $4.342 * * *$ & $-0.305^{* *}$ \\
\hline & $(0.548)$ & $(0.113)$ & (1.330) & $(0.119)$ \\
\hline \multirow[t]{2}{*}{ L.reer } & $-0.042 * * *$ & $-0.001 * * *$ & $0.022 * *$ & $-0.001 * * *$ \\
\hline & $(0.011)$ & $(0.000)$ & $(0.010)$ & $(0.000)$ \\
\hline \multirow[t]{2}{*}{ L.doil_price } & -1.012 & 0.271 & 0.407 & 0.206 \\
\hline & $(0.681)$ & $(0.178)$ & (1.199) & $(0.177)$ \\
\hline \multirow[t]{2}{*}{ Constant } & $16.437 * * *$ & $-129.015^{* * *}$ & 15.515 & \\
\hline & $(2.848)$ & $(27.522)$ & (13.406) & \\
\hline Observations & 230 & 1,567 & 393 & 1,634 \\
\hline R-squared & 0.602 & 0.465 & 0.294 & 0.473 \\
\hline dummy & rem $>10$ & rem $>10$ & rem $>1$ & rem> 1 \\
\hline method & OLS & OLS & OLS & OLS \\
\hline
\end{tabular}

Standard errors in parentheses, $* * * \mathrm{p}<0.01, * * \mathrm{p}<0.05, * \mathrm{p}<0.1$

Country dummies included but not shown in OLS regressions.

\subsection{Nominal Exports Growth Volatility}

Regarding the volatility of growth of nominal exports, large remittances are associated with lower volatility in both AFR and MENA. This is indeed the case when large remittances are defined as those with a remittances-to-GDP ratio of 10 percent of GDP or higher. Using the more flexible 1 percent definition, the relation still holds for AFR countries, but not for MENA countries (Table 3).

High remittance concentration is only detrimental to volatility in AFR countries. The coefficient of interest is positive and significant in equations 10 and 12 of Table 3, implying high concentration is associated with high volatility of exports growth. For MENA countries, the coefficient shows a negative sign, and is not statistically significant.

High remittances and high concentration combined are correlated with an increase in nominal exports growth volatility in both the AFR and MENA regions. This is evident from the empirical results of Table 3, showing a positive and significant coefficient attached to the relevant indicator variable. This is true for both regions when using both definitions, except for AFR when using the stricter 10 percent definition. 
Better institutions are associated with lower export growth volatility only in the case of AFR countries. This is the result of equation 12 in Table 3, although equation 10 for AFR also shows the correct negative sign as one would expect even though it is not statistically significant. This coefficient is not significant in both equations 9 and 11 for the MENA region. REER and oil price changes do not seem to impact export growth volatility in either region.

Table 3. Volatility of Export Growth

\begin{tabular}{|c|c|c|c|c|}
\hline & MENA & AFR & MENA & AFR \\
\hline & $(9)$ & $(10)$ & $(11)$ & $(12)$ \\
\hline VARIABLES & ex_gdp vol & ex_gdp vol & ex_gdp vol & ex_gdp vol \\
\hline \multirow[t]{2}{*}{ rem_dummy 10} & $-0.155^{* *}$ & $-0.059 * * *$ & & \\
\hline & $(0.063)$ & $(0.020)$ & & \\
\hline \multirow[t]{2}{*}{ rem_dummy1 } & & & 0.078 & $-0.062 * * *$ \\
\hline & & & $(0.048)$ & $(0.012)$ \\
\hline \multirow[t]{2}{*}{ hhi_mean1015 } & -0.269 & $24.046 * * *$ & -0.144 & $26.707 * * *$ \\
\hline & $(0.287)$ & $(3.565)$ & $(0.200)$ & $(3.653)$ \\
\hline \multirow[t]{2}{*}{ rem_dummy10hhi1015 } & $0.525 * *$ & 0.010 & & \\
\hline & $(0.217)$ & $(0.058)$ & & \\
\hline \multirow[t]{2}{*}{ rem_dummy1hhi1015 } & & & $0.180 *$ & $0.131 * * *$ \\
\hline & & & $(0.105)$ & $(0.025)$ \\
\hline \multirow[t]{2}{*}{ L.cpia } & 0.030 & -0.002 & 0.027 & $-0.041 * * *$ \\
\hline & $(0.030)$ & $(0.005)$ & $(0.030)$ & $(0.008)$ \\
\hline \multirow[t]{2}{*}{ L.reer } & -0.000 & 0.000 & $-0.000 * *$ & 0.000 \\
\hline & $(0.000)$ & $(0.000)$ & \begin{tabular}{|l|}
$(0.000)$ \\
\end{tabular} & $(0.000)$ \\
\hline \multirow[t]{2}{*}{ L.doil_price } & -0.004 & 0.002 & -0.013 & 0.013 \\
\hline & $(0.026)$ & $(0.009)$ & $(0.025)$ & $(0.008)$ \\
\hline \multirow[t]{2}{*}{ Constant } & 0.116 & $-3.331 * * *$ & -0.048 & $-3.551 * * *$ \\
\hline & $(0.113)$ & $(0.522)$ & $(0.124)$ & $(0.534)$ \\
\hline Observations & 390 & 984 & 390 & 1,631 \\
\hline R-squared & 0.311 & 0.691 & 0.322 & 0.368 \\
\hline dummy & rem $>10$ & rem $>10$ & rem>1 & rem>1 \\
\hline method & OLS & OLS & OLS & OLS \\
\hline
\end{tabular}

Standard errors in parentheses, $* * * \mathrm{p}<0.01, * * \mathrm{p}<0.05, * \mathrm{p}<0.1$

Country dummies included but not shown in OLS regressions.

\subsection{Exchange Rate Depreciation Volatility}

Moving finally to volatility of changes in the nominal exchange rate, ${ }^{5}$ results suggest that large remittances are correlated with smoother volatility in both AFR and MENA regions.

\footnotetext{
${ }^{5}$ The nominal exchange rate is defined such that higher values indicate a depreciation against the U.S. dollar.
} 


\section{MIMacrothink}

Business and Economic Research ISSN 2162-4860 2019, Vol. 9, No. 3

The coefficient of interest is negative and significant in equations 10 and 12 of Table 4 of AFR, equation 9 of MENA, but not in equation 11 of MENA using the more relaxed definition of large remittances-to-GDP ratio of 1 percent.

High remittance concentration is associated with an increase in exchange rate depreciation volatility in AFR countries. The variable of interest here is positive and statistically significant for both AFR equations 10 and 12 of Table 4. The HHI coefficient is positive with the expected sign, but not statistically significant for MENA in equation 11, while it reports the opposite sign in equation 9 of Table 4.

High concentration with high remittances is correlated with worse volatility in both the AFR and MENA regions. Results suggest that the coefficient of interest is positive and statistically significant for both AFR equations, for equation 9 of MENA, but not for equation 11 of MENA using the more relaxed definition.

Regressions suggest better institutions are correlated with less exchange rate volatility in MENA, but have no impact in AFR countries. The CPIA coefficient is negative and statistically significant as one would expect in MENA (equations 13 and 15 in Table 4), but not in the AFR (equations 14 and 16 in Table 4).

Table 4. Volatility of Rate of Exchange Rate Depreciation

\begin{tabular}{|c|c|c|c|c|}
\hline & MENA & AFR & MENA & AFR \\
\hline & (13) & (14) & $(15)$ & $(16)$ \\
\hline VARIABLES & dner_avg vol & dner_eop vol & dner_avg vol & dner_eop vol \\
\hline \multirow[t]{2}{*}{ rem_dummy 10} & $-0.188 * *$ & $-0.778 * * *$ & & \\
\hline & $(0.093)$ & $(0.167)$ & & \\
\hline \multirow[t]{2}{*}{ rem_dummy1 } & & & $0.242 * * *$ & $-1.198 * * *$ \\
\hline & & & $(0.086)$ & $(0.206)$ \\
\hline \multirow[t]{2}{*}{ hhi_mean1015 } & -0.111 & $109.889 * * *$ & 0.785 & $101.894 * * *$ \\
\hline & $(0.602)$ & $(20.989)$ & $(0.527)$ & $(21.468)$ \\
\hline \multirow[t]{2}{*}{ rem_dummy10hhi1015 } & $0.607 * *$ & $0.803 * * *$ & & \\
\hline & $(0.293)$ & $(0.221)$ & & \\
\hline \multirow[t]{2}{*}{ rem_dummy1hhi1015 } & & & $-0.529 * * *$ & $1.544 * * *$ \\
\hline & & & $(0.165)$ & $(0.275)$ \\
\hline \multirow[t]{2}{*}{ L.openness } & $-0.163 * * *$ & $-0.581 * * *$ & $-0.182 * * *$ & $-0.366^{* * *}$ \\
\hline & $(0.057)$ & $(0.147)$ & $(0.056)$ & $(0.126)$ \\
\hline \multirow[t]{2}{*}{ L.cpia } & $-0.258 * * *$ & 0.052 & $-0.265 * * *$ & 0.050 \\
\hline & $(0.063)$ & $(0.091)$ & $(0.062)$ & $(0.089)$ \\
\hline \multirow[t]{2}{*}{ L.doil_price } & $-0.058 * *$ & $-0.145 * *$ & $-0.058 * *$ & $-0.138 * *$ \\
\hline & $(0.025)$ & $(0.070)$ & $(0.025)$ & $(0.070)$ \\
\hline \multirow[t]{2}{*}{ Constant } & $1.306 * * *$ & $-15.447 * * *$ & $0.984 * * *$ & $-14.396 * * *$ \\
\hline & $(0.238)$ & $(3.152)$ & $(0.215)$ & $(3.215)$ \\
\hline Observations & 420 & 1,577 & 420 & 1,577 \\
\hline R-squared & 0.393 & 0.285 & 0.392 & 0.301 \\
\hline dummy & rem $>10$ & rem>10 & rem>1 & rem>1 \\
\hline
\end{tabular}




\begin{tabular}{|l|l|l|l|l|}
\hline & MENA & AFR & MENA & AFR \\
\hline & $(13)$ & $(14)$ & $(15)$ & $(16)$ \\
\hline VARIABLES & dner_avg vol & dner_eop vol & dner_avg vol & dner_eop vol \\
\hline method & OLS & OLS & OLS & OLS \\
\hline
\end{tabular}

Standard errors in parentheses, *** $\mathrm{p}<0.01, * * \mathrm{p}<0.05, * \mathrm{p}<0.1$

Country dummies included but not shown in OLS regressions.

In summary, results for AFR countries are more in line with priors than for MENA countries. This is evident from the fact that estimated coefficients for AFR equations have been almost consistently more in line with theoretical priors, both in terms of expected coefficient signs and statistical significance.

\subsection{Robustness Checks}

In the results above in all 4 equations, the pooled OLS with country effects essentially becomes a Fixed Effects (FE) model $^{6}$ although time-invariant variables such as initial GDP and remittance concentration are dropped. All other explanatory variables would retain their same estimated coefficient values.

As a robustness check on different estimation techniques, ${ }^{7}$ we employ the estimators developed by Hausman and Taylor (1981) and Amemiya and MaCurdy (1986) in a selected number of MENA and FR regressions. These estimators can be useful when the parameter of interest is time-invariant. ${ }^{8}$ Both estimators assume that all regressors are uncorrelated with the idiosyncratic errors. Thus, values of these regressors in periods other than the current period are used as instrumental variables. Results are similar qualitatively to those reported using pooled OLS, although diagnostic tests, following the Schaffer and Stillman (2010) over-identification test, suggest that instruments used are not valid, meaning they are correlated with the errors. As another robustness check, we re-estimate a few selected models using a Random Effects (RE) panel approach, and qualitative results largely remain the same in terms of the sign and significance of the estimated coefficients. Diagnostic tests using the Hausman (1978) test and the Breusch and Pagan (1980) Lagrangian multiplier test for RE, however, indicate that the explanatory variables in the RE model are correlated with the individual specific effects in the error term, rendering the RE model inconsistent.

Furthermore, we use the HHI average over 2013-2015 instead of 2010-2015 and results are unchanged. Specifically, lagged openness and CPIA retain their statistical significance and signs for MENA, while initial GDP and the interaction dummy between large remittances and concentration retain their significance and signs for AFR. We also experiment breaking-up the remittance variable into 4 quartiles as an alternative to the large remittance dummy, to see

\footnotetext{
${ }^{6}$ The Fixed Effects (FE) model is sometimes referred to as the Within Estimator or the Least Squares Dummy Variable (LSDV) method. The RE model, which is a feasible Generalized Least Squares (GLS) developed by Swamy and Arora (1972), is generally assumed to be a more efficient estimator than the FE model.

${ }^{7}$ Empirical results for robustness checks are not shown for space considerations, but are available upon request.

${ }^{8}$ See Hosny (2011) for a similar application of using a wide array of static and dynamic panel estimation techniques applied to understanding the determinants of trade flows between member countries of the Greater Arab Free Trade Area, in the context of a gravity trade model.
} 
how estimated coefficients at the top quartile compare to those at the lower quartiles, but results were not conclusive.

\section{Conclusion and Policy Implications}

This paper aims at understanding if remittances in MENA and AFR countries can reduce a country's volatilities, and if remittance concentration can aggravate those volatilities. A survey of the existing empirical studies suggests that these double objectives of the paper are a clear contribution to the literature. Specifically, we empirically estimate the impact of large remittances and high remittance concentration on volatilities of real GDP growth, nominal export growth, exports-to-GDP ratio, and exchange rate depreciation, while controlling for other variables that may affect these volatilities. To conduct the empirical analysis, we use data over the 1970-2015 period for 12 MENA and 44 AFR countries.

Empirical results for AFR countries are more in line with theoretical priors than MENA countries. This is evident from Tables 1 through 4 showing results by region, by type of volatility and by definition/size of remittances. Specifically, large remittances are defined in two different ways; a strict definition limiting the focus to countries with remittance-to-GDP ratios equal to or above 10 percent of GDP, and a relaxed definition using those equal or above 1 percent of GDP. Our results, overall, stipulate that large remittances and high remittance concentrations in AFR countries have effects in line with theoretical expectations more than the MENA countries.

Specifically, considering the impact of having large remittance inflows, all 4 types of volatility are reduced for AFR countries compared to only 3 for MENA. First, results suggest that large remittances are associated with lower volatility of GDP growth in AFR countries only. Second, lower volatility of exports-to-GDP and nominal growth of exports are correlated with large remittances for AFR countries using both large remittance definitions, but using the strict 10 percent definition only for MENA countries. Finally, large remittances for both regions, using both definitions/sizes of large remittances, are associated with lower volatility of exchange rate depreciation.

Concerning the impact of high remittance concentration, it has been found that it is associated with increases in 3 out of 4 types of volatility, in AFR countries only with no effect on MENA countries. Specifically, volatility of GDP growth is unaffected by the degree of remittance concentration in any of the regions and using any of the large remittance definitions. Volatility of exports-to-GDP increases with high remittance concentration in AFR countries using both definitions, but decreases in MENA countries using one of the large remittance definitions. Volatility of exports growth and exchange rate depreciation is only reduced for AFR countries, and this holds true using both definitions of large remittances, while coefficients are not statistically significant at all for MENA countries.

Regarding the impact of having both high remittances but also high concentration, results suggest that this is correlated with increases in all 4 types of volatility in both AFR and MENA, although MENA results are not always conclusive. Specifically, volatility of GDP growth is similarly impacted between the two regions. Volatility of exports-to-GDP, exports 
growth and exchange rate depreciation are mostly similarly impacted in both regions, although the impact was in the opposite direction in one of the MENA specifications for volatility of exchange rate depreciations. An implication for policymakers is that although encouraging more remittance inflows might be favorable, diversifying these sources or origins of remittance flows would be equally important. Efforts and structural reforms to diversify the export base and export destinations should overtime contribute to diversifying trade and investment partners, and as such contribute to lowering the potential negative impact of high remittance geographic concentration. In this context, strengthening ties with diaspora networks in different countries would be useful. Mitra et al (2016) for instance discusses how policy initiatives in advanced countries can be replicated to facilitate communication networks with emigrants in MENA countries, and help diversify sources of remittances while also promoting trade and investment opportunities.

Finally, better institutions are associated with lower volatility in all 4 types of volatility examined, distributed between the two regions. Results suggest better quality of institutions is associated with lower volatility in the case of GDP growth (for both regions), exports-to-GDP (except MENA in one of the specifications), exports growth (AFR only) and exchange rate depreciations (MENA only). To this end, and to have stronger and more competitive institutions, streamlining of business regulations, tax codes, and bureaucratic red tape would discourage corruption and level the playing field for businesses. Reducing the dominance of state-owned enterprises, in part through privatization, and raising their efficiency will also be critical for reducing the operating cost of businesses.

We also find evidence that greater trade openness and integration is associated with lower economic volatilities. Key policies in this regard include lowering tariffs and non-tariff barriers, simplification of customs rules and procedures, upgrading logistical infrastructure, and export-promoting policies. In this context, Mitra et al (2016) provide quantitative evidence that transitioning to higher-value added exports could improve total factor productivity in MENA countries.

\section{Acknowledgement}

The views expressed in this paper are those of the author and should not be attributed to the IMF, its Executive Board, or its management.

\section{References}

Ahmed, J., \& Inmaculada, M.-Z. (2013). Blessing or Curse: The Stabilizing Role of Remittances, Foreign Aid and FDI to Pakistan. Discussion Papers, Center for European Governance and Economic Development Research, No. 153.

https://doi.org/10.2139/ssrn.2261920

Amemiya, T., \& MaCurdy, T. R. (1986). Instrumental Variable Estimation of an Error Component Model. Econometrica, 54, 869-880. https://doi.org/10.2307/1912840

Bang, J. T., Bang, A. M., \& Phanindra, V. W. (2016). Do Remittances Improve Income Inequality? An Instrumental Variable Quantile Analysis of the Kenyan Case. Economic 
Modelling, 58(November), 394-402. https://doi.org/10.1016/j.econmod.2016.04.004

Bouoiyour, J., Refk, S., \& Amal, M. (2016). What Mitigates Economic Growth Volatility in Morocco? Remittances or FDI. Journal of Economic Integration, 31(1), 65-102.

https://doi.org/10.11130/jei.2016.31.1.65

Breusch, T. S., \& Pagan, A. R. (1980). The Lagrange Multiplier Test and its Applications to Model Specification in Econometrics. Review of Economic Studies, 47, 239-253. https://doi.org/10.2307/2297111

Chami, R., Adolfo, B., Thomas, C., Connel. F., Michael, G., \& Peter, M. (2008). Macroeconomic Consequences of Remittances. IMF Occasional Paper no. 259, Washington, D.C.: International Monetary Fund.

Chami, R., Connel, F., \& Samir, J. (2003). Are Immigrant Flows a Source of Capital for Development?. IMF WP no. 03/189, Washington, D.C.: International Monetary Fund. https://doi.org/10.5089/9781451859638.001

Chami, R., Dalia, S. H., \& Peter, J. M. (2012). Do Worker Remittances Reduce Output Volatility in Developing Countries?. Journal of Globalization and Development, 13(1), 1-23. https://doi.org/10.1515/1948-1837.1151

Ebeke, C. H. (2011). Essays on the Macroeconomic Consequences of Remittances in Developing Countries. Economies and finances. Universite d'Auvergne.

Hassan, G. M., \& Shamim, S. (2017). Nonlinear Effects of Remittances on Per Capita GDP Growth in Bangladesh. Economies, 5(25). https://doi.org/10.3390/economies5030025

Hausman, J. A. (1978). Specification Tests in Econometrics. Econometrica, 46(6), 1251-1271. https://doi.org/10.2307/1913827

Hausman, J. A., \& Taylor, W. E. (1981). Panel Data and Unobservable Individual Effects. Econometrica, 49, 1377-1398. https://doi.org/10.2307/1911406

Hosny, A. S. (2011). Does GAFTA Defy Gravity?. Middle Eastern Finance and Economics, 10(2011), 146-157.

IMF (2005). Two Current Issues Facing Developing Countries. Chapter 2 in World Economic Outlook, October 2005, Washington, D.C.: International Monetary Fund.

IMF (2013). Staff Guidance Note on the Application of the Joint Bank-Fund Debt Sustainability Framework for Low-Income Countries. IMF Board Paper. Washington, D.C.: International Monetary Fund.

Jansen, D. W., Diego, E. V., \& George, S. N. (2012). The Macroeconomic Consequences of Remittances. International Scholarly Research Network ISRN Economics, 2012, 1-14. https://doi.org/10.5402/2012/218071

Jidoud, A. (2015). Remittances and Macroeconomic Volatility in African Countries. IMF WP no. 15/49, Washington, D.C.: International Monetary Fund. 
https://doi.org/10.5089/9781498300940.001

Mitra, P., Amr, H., Gohar, M., Mark, F., \& Gohar, A. (2016). Avoiding the New Mediocre: Raising Long-Term Growth in the Middle East and Central Asia. The Middle East and Central Asia Departmental Paper no. 16/01. Washington, D.C.: International Monetary Fund.

Ncube, M., \& Zuzana, B. (2013). Remittances and their Macroeconomic Impact: Evidence from Africa. AfDB WP no. 188. Tunisia: African Development Bank.

Swamy, P. A. V. B., \& Arora, S. S. (1972). The Exact Finite Sample Properties of the Estimators of Coefficients in the Error Components Regression Models. Econometrica, 40, 261-275. https://doi.org/10.2307/1909405

Tansel, A., \& Pinar, Y. (2010). Macroeconomic Impact of Remittances on Output Growth: Evidence from Turkey. IZA Discussion Paper no. 5376, Germany: The Institute for the Study of Labor.

Thapa, S., \& Sanjaya, A. (2017). Remittances and Household Expenditure in Nepal: Evidence from Cross-Section Data. Economies, 5(16). https://doi.org/10.3390/economies5020016

World Bank (2006a). Economic Implications of Remittances and Migration. WB Global Economic Prospects, Washington, D.C.: The World Bank.

World Bank (2006b). The Development Impact of Workers'Remittances in Latin America. Vol. 2: Detailed Findings, Report No. 37026, Washington, D.C.: The World Bank.

World Bank (2015). Can Remittances Help Promote Consumption Stability?. Chapter 4 in WB Global Economic Prospects, Washington, D.C.: The World Bank.

\section{Copyright Disclaimer}

Copyright for this article is retained by the author(s), with first publication rights granted to the journal.

This is an open-access article distributed under the terms and conditions of the Creative Commons Attribution license (http://creativecommons.org/licenses/by/3.0/). 